\title{
Accumulation of solvent-soluble and solvent-insoluble antioxidant phenolics in edible bean sprouts: implication of germination
}

\author{
Ren-You Gan, ${ }^{1,2}$ Wing-Yee Lui, ${ }^{2}$ Ming-Fu Wang, ${ }^{2}$ Zhong-Quan Sui, ${ }^{1, *}$ and Harold \\ Corke $^{1,2, *}$
}

${ }^{1}$ Department of Food Science and Engineering, Shanghai Jiao Tong University, Shanghai 200240, China; ${ }^{2}$ School of Biological Sciences, The University of Hong Kong, Pokfulam Road, Hong Kong, China

*Corresponding author(s): Dr. Zhong-Quan Sui and Prof. Harold Corke, Department of Food Science and Engineering, Shanghai Jiao Tong University, Shanghai 200240, China

Submission Date: June 28, 2016, Accepted Date: August 26, 2016, Publication Date: August 30, 2016

\begin{abstract}
Background: Edible bean sprouts are popular fresh vegetables widely recognized for their nutritional quality. However, while their antioxidant capacity and phenolic composition in both solvent-soluble and solvent-insoluble extracts has not been systematically evaluated.
\end{abstract}

Methods: The antioxidant capacity and phenolic composition in both solvent-soluble and solvent-insoluble fractions of 12 cultivars of edible bean sprouts were evaluated, and relationships of antioxidant capacity and total phenolic content were also analyzed.

Results: Sprouts demonstrated a wide range of antioxidant capacity and total phenolic content, with lower but substantial antioxidant capacity and total phenolic content in the solvent-insoluble fractions. Highest levels were found in the green mung bean sprout. Phenolic compounds, such as catechin, ellagic acid, ferulic acid, gallic acid and $p$-coumaric acid were widely detected in these sprouts. Additionally, a positive correlation was discovered between antioxidant capacity and total phenolic content in these edible bean sprouts.

Conclusions: Germination generally resulted in the accumulation of antioxidant phenolics in the most edible bean sprouts. Edible bean sprouts with high antioxidant phenolics can be valuable natural sources of dietary antioxidants for the prevention of oxidative stress-related chronic diseases.

Keywords: Bean sprout, Germination, Antioxidant capacity, Radical scavenging capacity, Phenolic composition, Solvent-insoluble phenolics 


\section{INTRODUCTION}

Vegetables are good sources of various nutrients and phytochemicals. Diets which are rich in vegetables, such as the Mediterranean diet, have been associated with reduced risk for many chronic diseases [1, 2]. Edible sprouts have been consumed as fresh vegetables, particularly in Asian countries, for a long time. Compared to common vegetables, edible sprouts have some special advantages. First, they can be freshly consumed at all times of the year. Second, it is easy for them to be domestically cultivated only with water. Third, they are generally safe and readily available within one-week of growth. All these advantages make edible sprouts valuable contributors to the array of available fresh vegetables.

Recent studies show that edible sprouts have a different profile of nutrients, phytochemicals and antioxidant capacity compared with the original seeds. Through germination, the free amino acids and vitamins increase while minerals, carbohydrates and unsaturated fatty acids generally decrease [3-5]. However, some anti-nutrient factors, such as protease inhibitors, phytic acid and lectins, decline after germination [6, 7]. Nevertheless, the influence of germination on antioxidant phenolics in edible seeds remains contradictory. Several studies found that the antioxidant capacity and total phenolic content (TPC) were significantly enhanced in selected sprouts compared with respective raw seeds $[7,8]$, while other studies found that germination of seeds did not significantly increase, or even reduce, their antioxidant capacity and TPC [9-11]. This apparent discrepancy indicates that germination may distinctly influence antioxidant phenolics in diverse sprouts.

Edible bean sprouts, such as mung bean and soybean sprouts, are the most popular sprouts consumed in some eastern Asian countries, especially China. Several previous studies reported the antioxidant capacity and TPC in one or a few species of bean sprouts; however, the different germination, extraction and evaluation methods used make it difficult to directly compare the results from different investigations [10, 12-15]. More importantly, most of these studies only reported the antioxidant capacity and TPC that are solvent-soluble [10, 14], and ignored those which were solvent-insoluble, which has been reported to possess high antioxidant capacity and TPC in barley, millets and germinated brown rice [16-18]. Therefore, it is speculated that overlooking the solvent-insoluble extract may underestimate the total antioxidant capacity and phenolic content in edible bean sprouts.

In order to systematically and thoroughly evaluate antioxidant phenolics in edible bean sprouts, twelve diverse genotypes of edible bean sprouts were cultivated in this study. Their antioxidant capacity and phenolic composition in both solvent-soluble and solvent-insoluble fractions were evaluated and compared with the raw beans. The edible bean sprouts with high antioxidant phenolics, as good natural sources of dietary antioxidants, can be recommended for cultivation and consumption as functional vegetables.

\section{MATERIALS AND METHODS}

\section{Chemicals and Reagents}

2,2'-azinobis (3-ethylbenothiazoline-6-sulfonic acid) diammonium salt (ABTS), 2,4,6-tri(2-pyridyl)-s-triazine (TPTZ), ferric chloride anhydrous, ferrous sulfate heptahydrate, potassium persulphate, sodium acetate, sodium carbonate and sodium hydroxide were obtained 
from Sigma-Aldrich (St. Louis, MO, USA). Acetic acid, diethyl ether, ethyl acetate, Folin-Ciocalteu reagent and formic acid were from BDH (Dorset, UK). Ethanol, hydrochloric acid and methanol for extraction were from Merck KGaA (Darmstadt, Germany). 6-hydroxy-2,5,7,8-tetramethylchromane-2-carboxylic acid (Trolox) was from Fluka Chemie AG (Buchs, Switzerland). HPLC-grade methanol and $n$-hexane were from International Laboratory USA (South San Francisco, CA, USA). Authentic standards, including caffeic acid, ellagic acid, ferulic acid, gallic acid, p-coumaric acid, syringic acid, trans-cinnamic acid, vanillic acid, catechin, epicatechin and rutin were purchased from Sigma-Aldrich (St. Louis, MO, USA). Vitexin was purchased from Biopurify Phytochemicals (Chengdu, China). Deionized water was used for all the experiments.

\section{Germination of edible beans}

Twelve diverse genotypes of edible dry beans (Table 1) were purchased from markets in China, and their germination was performed according to the previous study [19] with minor modification. Briefly, edible beans were rinsed with deionized water three times, and then soaked in deionized water $(1: 10, \mathrm{w} / \mathrm{v})$ for $10 \mathrm{hr}$ at room temperature $\left(22 \pm 1^{\circ} \mathrm{C}\right)$. Rehydrated beans were then drained, spread on a tray and germinated in a domestic semi-automatic germination machine (model DYJ-A01, Rong Wei, Zhongshan, China) for 5 days in the dark. Germination was temperature-controlled at about $25{ }^{\circ} \mathrm{C}$ and automatically watered every $10 \mathrm{~min}$. Deionized water was used for germination and changed every $12 \mathrm{hr}$ to avoid microbial growth. Germination was performed in triplicate.

\section{Sample preparation}

The roots and/or bean coats were manually removed from soaked beans (Day 0) and germinated beans (Day 5). The length of bean sprouts was measured, and soaked beans and bean sprouts were then air-dried in a ventilated oven at $50{ }^{\circ} \mathrm{C}$ for $24 \mathrm{hr}$, ground into fine powder using a Kenwood Multi-Mill (Kenwood, Havant, UK), thoroughly mixed and stored at $4{ }^{\circ} \mathrm{C}$ for use.

\section{Extraction procedure}

\section{Extraction of solvent-soluble fraction}

The solvent-soluble fraction was extracted as previously reported [20] with slight modification. Briefly, $0.5 \mathrm{~g}$ sample was extracted with $10 \mathrm{~mL} 80 \%$ methanol in a shaker $(150 \mathrm{rpm})$ for $24 \mathrm{hr}$ at room temperature $\left(22 \pm 1{ }^{\circ} \mathrm{C}\right)$. The extract was then centrifuged at $2370 \times \mathrm{g}$ for $30 \mathrm{~min}$ at $4{ }^{\circ} \mathrm{C}$, and the supernatant was harvested and immediately stored at $-20{ }^{\circ} \mathrm{C}$ until use.

\section{Extraction of solvent-insoluble fraction}

After extraction of the solvent-soluble fraction, the residue was further used to extract the solvent-insoluble fraction according to the previous report [20] with slight modification. Briefly, the residue was treated with $10 \mathrm{~mL}$ of $2 \mathrm{M}$ sodium hydroxide $(\mathrm{NaOH})$ solution, and then the test tube was sealed and stirred for about $16 \mathrm{hr}$ at room temperature $\left(22 \pm 1{ }^{\circ} \mathrm{C}\right)$ in dark. The mixture was then acidified to $\mathrm{pH} 2$ with $6 \mathrm{M}$ hydrochloric acid $(\mathrm{HCl})$ and centrifuged $(2370 \times \mathrm{g}, 30 \mathrm{~min}, 4$ ${ }^{\circ} \mathrm{C}$ ). The supernatant was collected as alkaline hydrolytic component and kept at $4{ }^{\circ} \mathrm{C}$ for further 

extraction. Acid hydrolysis was next immediately performed by treating the residue with $2.5 \mathrm{~mL}$ of $12 \mathrm{M} \mathrm{HCl}$ for $30 \mathrm{~min}$ in a water bath at $85{ }^{\circ} \mathrm{C}$, then cooled down, adjusted to pH 2 and centrifuged $\left(2370 \times \mathrm{g}, 30 \mathrm{~min}, 4^{\circ} \mathrm{C}\right)$. The supernatant was collected and combined with the alkaline hydrolytic component. Fatty acid was removed from the combined supernatant by extraction with $10 \mathrm{~mL} n$-hexane three times, followed by extraction with $10 \mathrm{~mL}$ mixture of cold diethyl ether (DE) and ethyl acetate (EA, 1:1, v/v) three times. The DE \& EA layers were combined and evaporated to dryness at $30{ }^{\circ} \mathrm{C}$ in a rotary evaporator. The residue was dissolved in $5 \mathrm{~mL} 80 \%$ methanol and stored at $-20{ }^{\circ} \mathrm{C}$ until use.

\section{Determination of antioxidant capacity \\ Ferric-reducing antioxidant power (FRAP) assay}

The FRAP assay was performed as described [21, 22] with slight modification. Briefly, the FRAP reagent was prepared from sodium acetate buffer (300 mM, pH 3.6), 10 mM TPTZ solution (40 $\mathrm{mM} \mathrm{HCl}$ as solvent) and $20 \mathrm{mM}$ ferric chloride solution in a volume ratio of 10:1:1, respectively. The FRAP reagent was freshly prepared and warmed to $37^{\circ} \mathrm{C}$ in a water bath before use. $100 \mu \mathrm{L}$ of the properly diluted sample was mixed with $3 \mathrm{~mL}$ FRAP reagent. After incubation at room temperature $\left(22 \pm 1{ }^{\circ} \mathrm{C}\right)$ for $4 \mathrm{~min}$, the absorbance of the reaction mixture was determined at 593 $\mathrm{nm}$ using an ultraviolet-visible spectrophotometer (U-1800, Hitachi, Japan). The standard curve was constructed using ferrous sulfate solution, and the results were expressed as $\mu \mathrm{mol} \mathrm{Fe}$ (II)/g dry weight (DW) of samples.

\section{ABTS free radical scavenging assay}

The ABTS free radical scavenging assay was employed according to the literature [22, 23] with slight modification. Briefly, the $\mathrm{ABTS}^{\circ+}$ stock solution was prepared by mixing $7 \mathrm{mM}$ ABTS solution and $2.45 \mathrm{mM}$ potassium persulfate solution $(1: 1, \mathrm{v} / \mathrm{v})$ and then incubated in the dark for at least $16 \mathrm{hr}$ at room temperature $\left(22 \pm 1^{\circ} \mathrm{C}\right)$ and used within one day. The $\mathrm{ABTS}^{\circ+}$ working solution was prepared by dilution of the stock solution with $80 \%$ methanol to an absorbance of $0.70 \pm 0.05$ at $734 \mathrm{~nm}$. All samples were diluted to inhibit 20 to $80 \%$ absorbance of the blank. $100 \mu \mathrm{L}$ of the properly diluted sample was mixed with $3.8 \mathrm{~mL} \mathrm{ABTS}^{\circ+}$ working solution and incubated at room temperature $\left(22 \pm 1^{\circ} \mathrm{C}\right)$ for $6 \mathrm{~min}$. The absorbance of the reaction mixture was then detected at 734 $\mathrm{nm}$, and the percentage of the absorbance inhibition was calculated. Trolox was used as a reference standard, and the results were expressed as $\mu \mathrm{mol}$ Trolox/g DW of samples.

\section{Determination of TPC}

TPC was determined based on previous reports [22, 24]. Briefly, Folin-Ciocalteu reagent was freshly diluted 10 fold before use. $500 \mu \mathrm{L}$ of the properly diluted sample was mixed with $2.5 \mathrm{~mL}$ Folin-Ciocalteu reagent, and the solution was incubated at room temperature $\left(22 \pm 1^{\circ} \mathrm{C}\right)$ for $4 \mathrm{~min}$, followed by adding $2 \mathrm{~mL} 75 \mathrm{~g} / \mathrm{L}$ sodium carbonate solution and incubating for $2 \mathrm{hr}$ at room temperature $\left(22 \pm 1^{\circ} \mathrm{C}\right)$ in dark. The absorbance of the reaction mixture was then measured at 760 $\mathrm{nm}$. Gallic acid was used as a reference standard, and the results were expressed as milligram gallic acid equivalent (mg GAE)/100g DW of samples. 
The phenolic compounds were analyzed with high-performance liquid chromatography (HPLC) as previously reported [19], with a small modification. Briefly, HPLC analysis was performed using a Prominence Modular HPLC system (Shimadzu, Tokyo, Japan), consisting of a binary HPLC pump separation module (LC-20AT), an auto-sampler (SIL-20A), an online degasser (DGU-20A3) and a photodiode array detector (SPD-M20A). Before HPLC analysis, samples were filtered through $0.20 \mu \mathrm{m}$ nylon syringe filters (Merck Millipore, Cork, Ireland). Separation was carried out using an Zorbax SB-C18 column $(4.6 \times 150 \mathrm{~mm}, 3.5 \mu \mathrm{m})$ (Agilent Technologies, Santa Clara, CA, USA) at $35^{\circ} \mathrm{C}$ with the gradient elution solution A ( $2.5 \%$ formic acid-water solution) and solution $\mathrm{B}(100 \%$ methanol) following the program: $0 \mathrm{~min}, 5 \% \mathrm{~B} ; 15 \mathrm{~min}, 30 \% \mathrm{~B} ; 40 \mathrm{~min}$, $40 \% \mathrm{~B} ; 60 \mathrm{~min}, 50 \% \mathrm{~B} ; 65 \mathrm{~min}, 55 \% \mathrm{~B} ; 90-95 \mathrm{~min}, 95 \% \mathrm{~B}$. The flow rate was $0.8 \mathrm{~mL} / \mathrm{min}$, and the injection volume was $20 \mu \mathrm{L}$. Detection was set at $250 \mathrm{~nm}$ for ellagic acid, at $280 \mathrm{~nm}$ for catechin, epicatechin, gallic acid, syringic acid, trans-cinnamic acid and vanillic acid, at $320 \mathrm{~nm}$ for caffeic acid, ferulic acid, $p$-coumaric acid, vitexin and isovitexin, and at $350 \mathrm{~nm}$ for rutin. Phenolic compounds were identified primarily based on the comparison of retention time and UV spectra with authentic standards, and quantified according to the peak areas under corresponding detection wavelength. The stock solutions of phenolic compound standards were prepared in methanol or DMSO and stored at $-20{ }^{\circ} \mathrm{C}$, and the calibration standards $(10-500 \mu \mathrm{g} / \mathrm{mL})$ were prepared from the stock solution by serial dilutions.

\section{Statistical analysis}

All the measurements were performed in triplicate, except the HPLC analysis in duplicate, and the results were expressed as mean \pm standard deviation (SD). Statistical analysis was performed using Microsoft Excel 2003 (Redmond, WA, USA) and SPSS 20.0 (IBM SPSS Statistics, IBM, Somers, NY, USA). Multiple comparisons were carried out by one-way analysis of variance (ANOVA) plus post hoc Tukey test, and linear regression and principal component analysis were used to analyze relationships among parameters of antioxidant capacity and TPC. $p$ value $<0.05$ was defined as statistical significance.

\section{RESULTS AND DISCUSSION}

Twelve genotypes of edible bean sprouts (Table 1) were cultivated and their length was measured after five-day growth in dark. These sprouts generally reached a length normal for consumption (Table 1), with sprouts from adzuki bean, climbing bean and two mung bean cultivars being longest, while the three pea sprouts were shortest. Furthermore, since the sprouts were high but variable in moisture content, in order to eliminate the different dilution effects of moisture on antioxidant capacity and total phenolic content of sprouts and directly compare them with soaked beans, the results were based on the dry weight of sprouts. 
Table 1. Background information on twelve genotypes of edible bean sprouts

\begin{tabular}{llc}
\hline Common name & Scientific name & Sprout length (cm) \\
\hline Adzuki bean & Vigna angularis & $17.6 \pm 1.80^{\mathrm{f}}$ \\
Climbing bean & Vigna angularis & $17.0 \pm 1.62^{\mathrm{f}}$ \\
Mottled cowpea & Vigna unguiculata & $11.1 \pm 1.50^{\mathrm{c}, \mathrm{d}}$ \\
Speckled kidney bean & Phaseolus vulgaris & $7.23 \pm 0.73^{\mathrm{b}}$ \\
Black mung bean & Vigna radiata & $17.2 \pm 1.12^{\mathrm{f}}$ \\
Green mung bean & Vigna radiata & $17.4 \pm 1.52^{\mathrm{f}}$ \\
Green pea & Pisum sativum & $6.68 \pm 0.56^{\mathrm{b}}$ \\
Mottled pea & Pisum sativum & $5.98 \pm 0.53^{\mathrm{a}}$ \\
White pea & Pisum sativum & $4.80 \pm 0.50^{\mathrm{a}}$ \\
Rice bean & Vigna umbellata & $15.4 \pm 2.10^{\mathrm{e}}$ \\
Black soy bean & Glycine max & $12.1 \pm 1.05^{\mathrm{d}}$ \\
Yellow soy bean & Glycine max & $10.4 \pm 1.17^{\mathrm{c}}$ \\
\hline
\end{tabular}

The length of each sprout $(n \geq 18)$ was measured and expressed as mean \pm SD. One-way ANOVA plus post-hoc Tukey test was performed to compare the length of different sprouts, and different superscript lowercase letters indicated statistical significance with $p<0.05$.

\section{Antioxidant capacity of twelve edible bean sprouts}

Fresh vegetables are good sources of natural antioxidants. However, edible bean sprouts, have not been systematically evaluated for their antioxidant capacity. Additionally, the antioxidant capacity of their solvent-insoluble extract has been little investigated. The ferric-reducing antioxidant power (FRAP) assay was first used to determine the iron-reducing capacity of bean sprouts (Day 5) as shown in Table 2. FRAP assay is based on the capacity of antioxidants to reduce ferric ions to ferrous ions, which can form a purple complex with TPTZ [21]. For the solvent-soluble fraction of sprouts, the FRAP values ranged from $5.73 \pm 0.58$ to $29.4 \pm 1.57 \mu \mathrm{mol} \mathrm{Fe}$ (II)/g DW, a 5-fold range. The green mung bean sprout, mottled cowpea sprout and speckled kidney bean sprout had the highest FRAP values, while white pea sprout had the lowest FRAP value. For the solvent-insoluble fraction, the FRAP values were generally lower than that in the solvent-soluble fraction of corresponding sprouts and ranged from $1.01 \pm 0.06$ to $15.1 \pm 0.58 \mu \mathrm{mol} \mathrm{Fe}$ (II)/g DW, a 15-fold range. The green mung bean sprout, black mung bean sprout and climbing bean sprout had the highest FRAP values, while mottled pea sprout had the lowest FRAP value. Combining the 

two fractions together, the total FRAP values of sprouts ranged from $6.82 \pm 0.53$ to $44.5 \pm 1.39$ $\mu \mathrm{mol} \mathrm{Fe}$ (II)/g DW, a 6.5-fold range. Green mung bean sprout had the highest total FRAP value $(44.5 \pm 1.39 \mu \mathrm{mol} \mathrm{Fe}(\mathrm{II}) / \mathrm{g} \mathrm{DW})$, followed by speckled kidney bean sprout $(22.3 \pm 1.07 \mu \mathrm{mol} \mathrm{Fe}$ (II)/g DW), mottled cowpea sprout (22.3 $\pm 1.07 \mu \mathrm{mol} \mathrm{Fe}(\mathrm{II}) / \mathrm{g}$ DW) and black mung bean sprout $(21.2 \pm 0.72 \mu \mathrm{mol} F e(\mathrm{II}) / \mathrm{g} \mathrm{DW})$, while white pea sprout had the lowest total FRAP value (6.82 \pm $0.53 \mu \mathrm{mol} \mathrm{Fe}(\mathrm{II}) / \mathrm{g} \mathrm{DW})$.

Antioxidants possess not only reducing capacity, but also free-radical scavenging capacity. In order to more thoroughly evaluate the antioxidant capacity of edible bean sprouts, ABTS free radical scavenging assay was employed to determine their free-radical scavenging capacity. ABTS assay is dependent on the capacity of antioxidants to scavenge $\operatorname{ABTS}^{\circ+}$ free radicals [23], and is commonly used together with FRAP assay to evaluate antioxidant capacity in vitro. For the solvent-soluble fraction of sprouts, the ABTS values ranged from $6.48 \pm 0.19$ to $25.9 \pm 1.05 \mu \mathrm{mol}$ Trolox/g DW (Table 2), a 4-fold range, with the green mung bean sprout, black mung bean sprout and yellow soy bean sprout having the highest ABTS value, while white pea sprout had the lowest value. For the solvent-insoluble fraction, the ABTS values were generally lower than that in the solvent-soluble fraction of corresponding sprouts, similar to the results of FRAP values, and ranged from $0.58 \pm 0.03$ to $6.46 \pm 0.21 \mu \mathrm{mol}$ Trolox/g DW, an 11-fold range. The green mung bean sprout, black mung bean sprout and speckled kidney bean sprout had the highest ABTS value, while white pea sprout had the lowest. Considering the two fractions together, the total ABTS values ranged from $7.06 \pm 0.16$ to $32.4 \pm 0.88 \mu$ mol Trolox/g DW, a 4.6 -fold range. The green mung bean sprout had the highest total ABTS value $(32.4 \pm 0.88 \mu \mathrm{mol}$ Trolox/g DW), followed by the black mung bean sprout $(23.8 \pm 1.87 \mu \mathrm{mol}$ Trolox/g DW), speckled kidney bean sprout $(14.8 \pm$ $0.55 \mu \mathrm{mol}$ Trolox/g DW) and yellow soy bean sprout (14.6 $\pm 0.82 \mu \mathrm{mol}$ Trolox/g DW). On the other hand, the white pea sprout had the lowest total ABTS value $(7.06 \pm 0.16 \mu \mathrm{mol}$ Trolox/g DW).

Several previous studies reported the antioxidant capacity of selected sprouts [8, 10, 13]. However, it is difficult to directly compare the results of different investigations due to different genotype, agronomic, germination, extraction and evaluation methods used. In our study, it was interesting to find that the solvent-soluble fractions of the bean sprouts generally had much higher antioxidant capacity than their solvent-insoluble fractions, and the green mung bean sprout had the highest total antioxidant capacity among twelve edible bean sprouts. Furthermore, few previous studies reported the antioxidant capacity in the solvent-insoluble fraction of bean sprouts, while we found that the solvent-insoluble fraction of bean sprouts also exhibited some extent of antioxidant capacity, especially in the green mung bean sprout, which had higher antioxidant capacity compared with other bean sprouts. Since the antioxidant capacity in the solvent-insoluble fraction has also been reported in other plant-based foods, such as cereal grains, millet grains and wild flowers $[17,25,26]$, it is speculated that natural antioxidants, such as phenolic compounds, may contribute to the antioxidant capacity of the solvent-insoluble fraction, overlooking of which would underestimate the total antioxidant capacity in bean sprouts. 
Table 2. Antioxidant capacity of twelve genotypes of edible bean sprouts

\begin{tabular}{|c|c|c|c|c|c|c|c|}
\hline \multirow{2}{*}{ Sprouts } & \multirow[t]{2}{*}{$\begin{array}{l}\text { Germination } \\
\text { time }\end{array}$} & \multicolumn{3}{|c|}{ FRAP value $(\mu \mathrm{mol} \mathrm{Fe}(\mathrm{II}) / \mathrm{g}$ DW) } & \multicolumn{3}{|c|}{ ABTS value ( $\mu$ mol Trolox/g DW) } \\
\hline & & $\begin{array}{r}\text { Solvent-soluble } \\
\text { fraction }\end{array}$ & $\begin{array}{l}\text { Solvent-insolubl } \\
\text { e fraction }\end{array}$ & Total & $\begin{array}{l}\text { Solvent-s } \\
\text { oluble fraction }\end{array}$ & $\begin{array}{l}\text { Solvent-ins } \\
\text { oluble fraction }\end{array}$ & Total \\
\hline \multirow[t]{2}{*}{ Adzuki bean } & Day 0 & $11.5 \pm 0.37$ & $1.00 \pm 0.15$ & $12.5 \pm 0.29$ & $7.36 \pm 0.18$ & $0.66 \pm 0.05$ & $8.02 \pm 0.13$ \\
\hline & Day 5 & $13.5 \pm 0.70^{\mathrm{d}}$ & $3.61 \pm 0.28^{\mathrm{c}, \mathrm{d}}$ & $17.1 \pm 0.77^{\mathrm{c}}$ & $10.4 \pm 1.30^{\mathrm{c}, \mathrm{d}, \mathrm{e}}$ & $1.74 \pm 0.06^{\mathrm{c}, \mathrm{d}}$ & $12.2 \pm 1.33^{\mathrm{c}, \mathrm{d}, \mathrm{e}}$ \\
\hline \multirow[t]{2}{*}{ Climbing bean } & Day 0 & $11.3 \pm 0.55$ & $0.78 \pm 0.04$ & $12.0 \pm 0.54$ & $7.77 \pm 0.24$ & $0.62 \pm 0.04$ & $8.39 \pm 0.21$ \\
\hline & Day 5 & $12.9 \pm 0.37^{\mathrm{d}}$ & $4.21 \pm 0.11^{\mathrm{c}}$ & $17.1 \pm 0.45^{\mathrm{c}}$ & $9.31 \pm 0.66^{\mathrm{e}}$ & $1.87 \pm 0.04^{\mathrm{c}, \mathrm{d}}$ & $11.2 \pm 0.64^{\mathrm{de}, \mathrm{f}}$ \\
\hline \multirow[t]{2}{*}{ Mottled cowpea } & Day 0 & $11.1 \pm 0.22$ & $0.61 \pm 0.06$ & $11.7 \pm 0.23$ & $7.09 \pm 0.29$ & $0.59 \pm 0.06$ & $7.68 \pm 0.27$ \\
\hline & Day 5 & $19.4 \pm 1.03^{\mathrm{b}}$ & $2.95 \pm 0.06^{\mathrm{e}}$ & $22.3 \pm 1.07^{\mathrm{b}}$ & $12.1 \pm 0.87^{\mathrm{c}, \mathrm{d}}$ & $1.73 \pm 0.05^{\mathrm{d}}$ & $13.8 \pm 0.92^{\mathrm{c}, \mathrm{d}}$ \\
\hline \multirow{2}{*}{$\begin{array}{l}\text { Speckled kidney } \\
\text { bean }\end{array}$} & Day 0 & $9.91 \pm 0.40$ & $0.86 \pm 0.04$ & $10.8 \pm 0.40$ & $6.40 \pm 0.50$ & $0.81 \pm 0.05$ & $7.21 \pm 0.46$ \\
\hline & Day 5 & $19.4 \pm 0.74^{b}$ & $3.35 \pm 0.16^{\mathrm{d}, \mathrm{e}}$ & $22.7 \pm 0.69^{b}$ & $12.7 \pm 0.59^{\mathrm{c}}$ & $2.04 \pm 0.04^{\mathrm{c}}$ & $14.8 \pm 0.55^{\mathrm{c}}$ \\
\hline \multirow[t]{2}{*}{ Black mung bean } & Day 0 & $5.10 \pm 0.15$ & $0.64 \pm 0.04$ & $5.75 \pm 0.11$ & $5.00 \pm 0.14$ & $0.82 \pm 0.05$ & $5.82 \pm 0.19$ \\
\hline & Day 5 & $15.8 \pm 0.62^{\mathrm{c}}$ & $5.42 \pm 0.12^{b}$ & $21.2 \pm 0.72^{\mathrm{b}}$ & $21.1 \pm 1.80^{\mathrm{b}}$ & $2.74 \pm 0.09^{b}$ & $23.8 \pm 1.87^{\mathrm{b}}$ \\
\hline \multirow[t]{2}{*}{ Green mung bean } & Day 0 & $4.39 \pm 0.21$ & $0.33 \pm 0.02$ & $4.72 \pm 0.20$ & $5.57 \pm 0.24$ & $0.56 \pm 0.08$ & $6.13 \pm 0.31$ \\
\hline & Day 5 & $29.4 \pm 1.57^{\mathrm{a}}$ & $15.1 \pm 0.58^{\mathrm{a}}$ & $44.5 \pm 1.39^{\mathrm{a}}$ & $25.9 \pm 1.05^{\mathrm{a}}$ & $6.46 \pm 0.21^{\mathrm{a}}$ & $32.4 \pm 0.88^{\mathrm{a}}$ \\
\hline \multirow[t]{2}{*}{ Green pea } & Day 0 & $4.17 \pm 0.34$ & $0.66 \pm 0.07$ & $4.83 \pm 0.40$ & $4.83 \pm 0.60$ & $0.74 \pm 0.07$ & $5.57 \pm 0.66$ \\
\hline & Day 5 & $10.0 \pm 0.54^{\mathrm{e}}$ & $1.36 \pm 0.05^{\mathrm{f}, \mathrm{g}}$ & $11.4 \pm 0.58^{\mathrm{d}}$ & $8.22 \pm 0.29^{e, f}$ & $0.99 \pm 0.04^{\mathrm{f}}$ & $9.21 \pm 0.32^{\mathrm{f}, \mathrm{g}}$ \\
\hline \multirow[t]{2}{*}{ Mottled pea } & Day 0 & $5.33 \pm 0.22$ & $0.71 \pm 0.04$ & $6.03 \pm 0.21$ & $6.80 \pm 0.25$ & $0.58 \pm 0.03$ & $7.38 \pm 0.28$ \\
\hline & Day 5 & $8.51 \pm 0.50^{\mathrm{e}, \mathrm{f}}$ & $1.01 \pm 0.06^{\mathrm{g}}$ & $9.52 \pm 0.48^{\mathrm{d}, \mathrm{e}}$ & $8.64 \pm 0.31^{\mathrm{e}, \mathrm{f}}$ & $0.80 \pm 0.04^{\mathrm{f}, \mathrm{g}}$ & $9.45 \pm 0.30^{\mathrm{f}, \mathrm{g}}$ \\
\hline \multirow[t]{2}{*}{ White pea } & Day 0 & $5.04 \pm 0.16$ & $0.71 \pm 0.05$ & $5.75 \pm 0.12$ & $5.99 \pm 0.61$ & $0.88 \pm 0.07$ & $6.86 \pm 0.66$ \\
\hline & Day 5 & $5.73 \pm 0.58^{\mathrm{g}}$ & $1.09 \pm 0.08^{\mathrm{g}}$ & $6.82 \pm 0.53^{f}$ & $6.48 \pm 0.19^{f}$ & $0.58 \pm 0.03^{g}$ & $7.06 \pm 0.16^{\mathrm{g}}$ \\
\hline \multirow[t]{2}{*}{ Rice bean } & Day 0 & $8.34 \pm 0.63$ & $1.17 \pm 0.09$ & $9.50 \pm 0.72$ & $7.26 \pm 0.19$ & $0.62 \pm 0.07$ & $7.88 \pm 0.21$ \\
\hline & Day 5 & $7.47 \pm 0.58^{\mathrm{f}, \mathrm{g}}$ & $1.58 \pm 0.15^{\mathrm{f}, \mathrm{g}}$ & $9.04 \pm 0.60^{\mathrm{e}, \mathrm{f}}$ & $9.16 \pm 0.97^{\mathrm{e}}$ & $0.75 \pm 0.07^{\mathrm{f}, \mathrm{g}}$ & $9.90 \pm 0.94^{\mathrm{e}, \mathrm{f}}$ \\
\hline \multirow[t]{2}{*}{ Black soy bean } & Day 0 & $7.59 \pm 0.48$ & $2.86 \pm 0.13$ & $10.5 \pm 0.35$ & $9.80 \pm 0.80$ & $2.68 \pm 0.12$ & $12.5 \pm 0.92$ \\
\hline & Day 5 & $8.64 \pm 0.82^{\mathrm{e}, \mathrm{f}}$ & $1.82 \pm 0.10^{\mathrm{f}}$ & $10.5 \pm 0.85^{\mathrm{d}, \mathrm{e}}$ & $9.65 \pm 0.15^{\mathrm{d}, \mathrm{e}}$ & $1.33 \pm 0.09^{\mathrm{e}}$ & $11.0 \pm 0.22^{\mathrm{e}, \mathrm{f}}$ \\
\hline \multirow[t]{2}{*}{ Yellow soy bean } & Day 0 & $10.6 \pm 0.64$ & $2.35 \pm 0.13$ & $13.0 \pm 0.54$ & $10.6 \pm 0.60$ & $1.54 \pm 0.11$ & $12.2 \pm 0.50$ \\
\hline & Day 5 & $13.9 \pm 0.61^{\mathrm{c}, \mathrm{d}}$ & $3.46 \pm 0.13^{\mathrm{d}, \mathrm{e}}$ & $17.3 \pm 0.57^{\mathrm{c}}$ & $12.8 \pm 0.60^{\mathrm{c}}$ & $1.84 \pm 0.22^{\mathrm{c}, \mathrm{d}}$ & $14.6 \pm 0.82^{c}$ \\
\hline
\end{tabular}

FRAP and ABTS values were expressed as mean \pm SD, and the FRAP and ABTS values of 12 bean sprouts in each column were compared by one-way analysis of variance (ANOVA) plus post hoc Tukey test, and different superscript lowercase letters indicated statistical significance $(p<0.05)$. 


\section{Phenolic composition in twelve edible bean sprouts}

Many phenolic compounds, such as gallic acid and catechin, are natural antioxidants with high antioxidant capacity. Therefore, we determined TPC in addition to the main phenolic compounds and their contents in the twelve edible bean sprouts. TPC was measured using the Folin-Ciocalteu method, which is based on the formation of a blue complex between phenolic compounds and Folin-Ciocalteu reagent in the alkaline environment [24]. For the solvent-soluble fraction, the TPC of bean sprouts ranged from $289 \pm 14.8$ to $1084 \pm 52.8 \mathrm{mg} \mathrm{GAE} / 100 \mathrm{~g} \mathrm{DW}$, a 4-fold range, and two mung bean sprouts had the highest content (Table 3). For the solvent-insoluble fraction, the TPC ranged from $28.3 \pm 0.58$ to $174 \pm 11.2 \mathrm{mg} \mathrm{GAE} / 100 \mathrm{~g} \mathrm{DW}$, a 6-fold range, and two mung bean sprouts again had the highest level. Combining the results of the two fractions, the TPC varied from $317 \pm 15.0$ to $1257 \pm 41.8 \mathrm{mg} \mathrm{GAE} / 100 \mathrm{~g} \mathrm{DW}$, a 4-fold difference, and the green mung bean sprout (1257 $\pm 41.8 \mathrm{mg} \mathrm{GAE} / 100 \mathrm{~g} \mathrm{DW})$ had the highest level, followed by the black mung bean sprout (928 $\pm 18.4 \mathrm{mg} \mathrm{GAE} / 100 \mathrm{~g} \mathrm{DW})$, mottled cowpea sprout (802 $\pm 19.5 \mathrm{mg} \mathrm{GAE} / 100 \mathrm{~g} \mathrm{DW})$ and adzuki bean sprout (755 $\pm 8.81 \mathrm{mg} \mathrm{GAE} / 100 \mathrm{~g} \mathrm{DW})$. On the other hand, the white pea sprout had the lowest TPC $(317 \pm 15.0 \mathrm{mg} \mathrm{GAE} / 100 \mathrm{~g} \mathrm{DW})$. Generally, the solvent-soluble fractions of bean sprouts had much higher TPC than their solvent-insoluble fractions, consistent with the results of antioxidant capacity. While there was still some extent of phenolics detected in the solvent-insoluble fractions. Therefore, overlooking of this component would underestimate the whole phenolics in edible bean sprouts.

Table 3. TPC of twelve genotypes of edible bean sprouts

\begin{tabular}{|c|c|c|c|c|}
\hline \multirow[b]{2}{*}{ Sprouts } & \multirow[b]{2}{*}{$\begin{array}{l}\text { Germination } \\
\text { time }\end{array}$} & \multicolumn{3}{|c|}{ TPC (mg GAE/100g DW) } \\
\hline & & $\begin{array}{l}\text { Solvent-soluble } \\
\text { fraction }\end{array}$ & $\begin{array}{l}\text { Solvent-insoluble } \\
\text { fraction }\end{array}$ & Total \\
\hline $\begin{array}{l}\text { Adzuki } \\
\text { bean }\end{array}$ & $\begin{array}{l}\text { Day } 0 \\
\text { Day } 5\end{array}$ & $\begin{array}{l}113 \pm 5.29 \\
690 \pm 9.05^{\mathrm{cdd}}\end{array}$ & $\begin{array}{l}30.9 \pm 1.18 \\
64.6 \pm 1.24^{\mathrm{c}, \mathrm{d}}\end{array}$ & $\begin{array}{l}144 \pm 6.03 \\
755 \pm 8.81^{\mathrm{c}, \mathrm{d}}\end{array}$ \\
\hline $\begin{array}{l}\text { Climbing } \\
\text { bean }\end{array}$ & $\begin{array}{l}\text { Day } 0 \\
\text { Day } 5\end{array}$ & $\begin{array}{l}113 \pm 4.14 \\
643 \pm 34.5^{d}\end{array}$ & $\begin{array}{l}28.3 \pm 0.67 \\
72.0 \pm 2.25^{\mathrm{b}, \mathrm{c}}\end{array}$ & $\begin{array}{l}141 \pm 4.76 \\
715 \pm 33.7^{d}\end{array}$ \\
\hline $\begin{array}{l}\text { Mottled } \\
\text { cowpea }\end{array}$ & $\begin{array}{l}\text { Day } 0 \\
\text { Day } 5\end{array}$ & $\begin{array}{l}130 \pm 3.15 \\
758 \pm 18.1^{c}\end{array}$ & $\begin{array}{l}15.4 \pm 1.18 \\
44.1 \pm 1.77^{\mathrm{e}}\end{array}$ & $\begin{array}{l}145 \pm 2.01 \\
802 \pm 19.5^{c}\end{array}$ \\
\hline $\begin{array}{l}\text { Speckled } \\
\text { kidney } \\
\text { bean }\end{array}$ & $\begin{array}{l}\text { Day } 0 \\
\text { Day } 5\end{array}$ & $\begin{array}{l}104 \pm 2.92 \\
548 \pm 17.3^{\mathrm{e}}\end{array}$ & $\begin{array}{l}29.6 \pm 0.86 \\
56.1 \pm 1.86^{d}\end{array}$ & $\begin{array}{l}133 \pm 3.63 \\
604 \pm 18.0^{\mathrm{e}}\end{array}$ \\
\hline $\begin{array}{l}\text { Black } \\
\text { mung bean }\end{array}$ & $\begin{array}{l}\text { Day } 0 \\
\text { Day } 5\end{array}$ & $\begin{array}{l}75.3 \pm 1.54 \\
847 \pm 16.7^{b}\end{array}$ & $\begin{array}{l}36.1 \pm 1.07 \\
80.7 \pm 1.77^{b}\end{array}$ & $\begin{array}{l}111 \pm 2.57 \\
928 \pm 18.4^{b}\end{array}$ \\
\hline
\end{tabular}




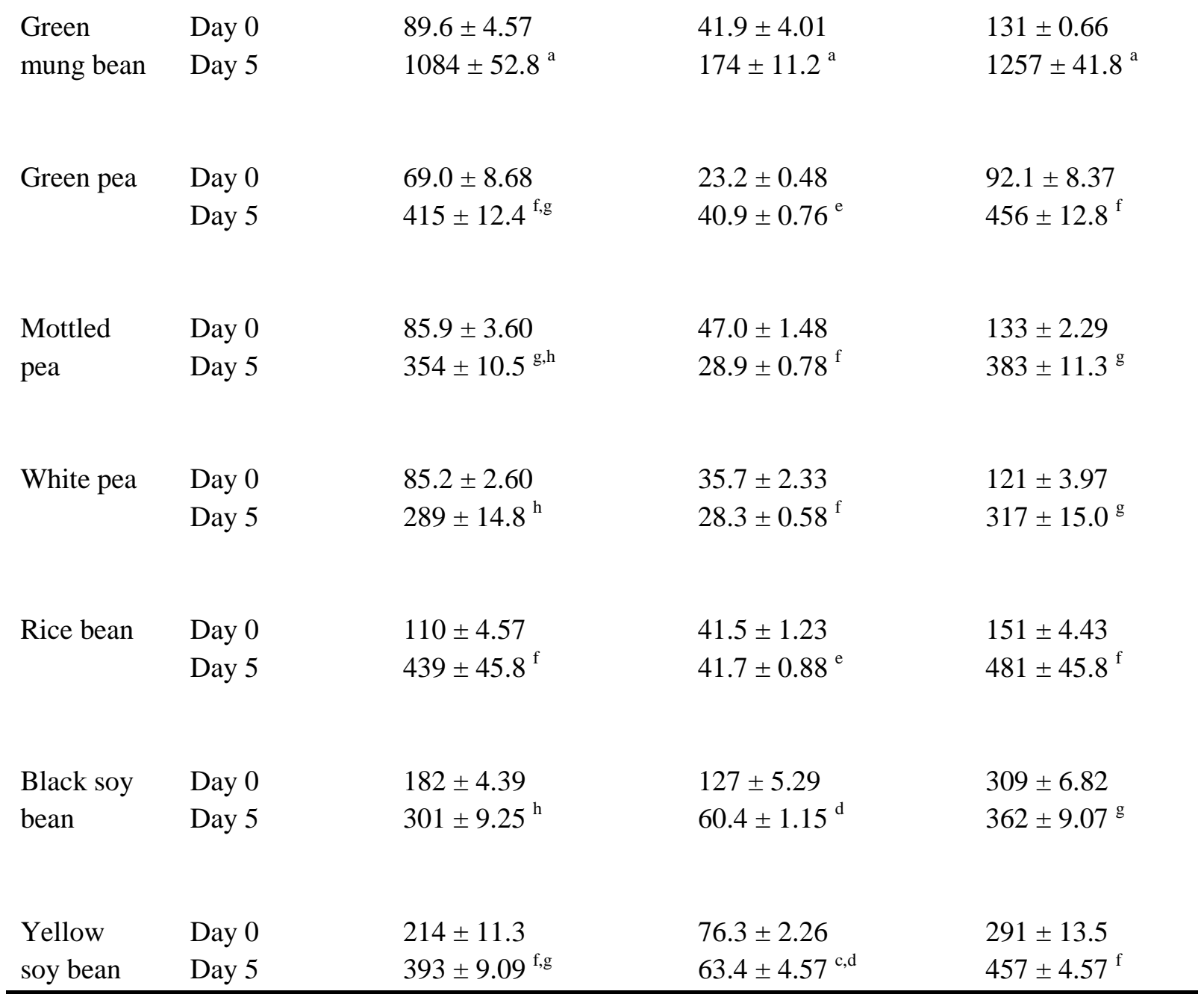

TPC was expressed as mean \pm SD, and the TPC of 12 bean sprouts in each column was compared by one-way analysis of variance (ANOVA) plus post hoc Tukey test, and different superscript lowercase letters indicated statistical significance $(p<0.05)$.

In order to further investigate the phenolic profile in edible bean sprouts, phenolic compounds and their content in both fractions were further investigated by HPLC. The results (Table 4) indicated that phenolic compounds, mainly phenolic acids and flavonoids, were widely detected in both fractions of sprouts, while their phenolic composition differed. Catechin, epicatechin, gallic acid, rutin and trans-cinnamic acid were mainly found in the solvent-soluble fraction, while caffeic acid, ferulic acid, syringic acid and vanillic acid were most found in the solvent-insoluble fraction. Additionally, ellagic acid, $p$-coumaric acid, vitexin and isovitexin could be found in both fractions. Furthermore, the contents of phenolic compounds in different sprouts were various. All these results suggested that different bean sprouts had different distribution and content of phenolics. 
Table 4. Main phenolic compounds and their content in twelve genotypes of edible bean sprouts

\begin{tabular}{|c|c|c|c|c|}
\hline \multirow[b]{2}{*}{ Sprouts } & \multicolumn{2}{|c|}{ Solvent-soluble fraction } & \multicolumn{2}{|c|}{ Solvent-insoluble fraction } \\
\hline & $\begin{array}{l}\text { Phenolic } \\
\text { compounds }\end{array}$ & $\begin{array}{c}\text { Content } \\
(\mathrm{mg} / 100 \mathrm{~g} \mathrm{DW})\end{array}$ & $\begin{array}{l}\text { Phenolic } \\
\text { compounds }\end{array}$ & $\begin{array}{c}\text { Content } \\
(\mathrm{mg} / 100 \mathrm{~g} \text { DW })\end{array}$ \\
\hline \multirow[t]{5}{*}{ Adzuki bean } & Catechin & $5.03 \pm 0.22$ & Ellagic acid & $8.96 \pm 0.03$ \\
\hline & Epicatechin & $4.37 \pm 0.39$ & Ferulic acid & $3.50 \pm 0.03$ \\
\hline & Gallic acid & $41.3 \pm 0.88$ & $p$-Coumaric acid & $11.3 \pm 0.21$ \\
\hline & $p$-Coumaric acid & $2.70 \pm 0.03$ & & \\
\hline & trans-Cinnamic acid & $2.77 \pm 0.01$ & & \\
\hline \multirow[t]{5}{*}{ Climbing bean } & Catechin & $6.98 \pm 0.23$ & Ellagic acid & $9.69 \pm 0.08$ \\
\hline & Epicatechin & $4.85 \pm 0.43$ & Ferulic acid & $3.57 \pm 0.19$ \\
\hline & Gallic acid & $39.2 \pm 2.56$ & $p$-Coumaric acid & $11.1 \pm 0.65$ \\
\hline & $p$-Coumaric acid & $2.59 \pm 0.05$ & & \\
\hline & trans-Cinnamic acid & $2.27 \pm 0.25$ & & \\
\hline \multirow[t]{5}{*}{ Mottled cowpea } & Ellagic acid & $18.1 \pm 0.10$ & Ferulic acid & $7.56 \pm 0.17$ \\
\hline & Epicatechin & $4.10 \pm 0.36$ & $p$-Coumaric acid & $9.49 \pm 0.23$ \\
\hline & Gallic acid & $48.3 \pm 1.86$ & & \\
\hline & $p$-Coumaric acid & $3.56 \pm 0.07$ & & \\
\hline & trans-Cinnamic acid & $1.83 \pm 0.14$ & & \\
\hline \multirow{5}{*}{$\begin{array}{l}\text { Speckled kidney } \\
\text { bean }\end{array}$} & Ellagic acid & $18.3 \pm 0.42$ & Caffeic acid & $3.12 \pm 0.02$ \\
\hline & Gallic acid & $32.0 \pm 2.41$ & Ellagic acid & $9.58 \pm 0.25$ \\
\hline & $p$-Coumaric acid & $2.77 \pm 0.02$ & Ferulic acid & $5.73 \pm 0.11$ \\
\hline & Rutin & $19.7 \pm 0.96$ & $p$-Coumaric acid & $4.93 \pm 0.08$ \\
\hline & trans-Cinnamic acid & $2.25 \pm 0.10$ & & \\
\hline \multirow[t]{5}{*}{ Black mung bean } & Catechin & $9.15 \pm 0.32$ & Caffeic acid & $6.20 \pm 0.17$ \\
\hline & Gallic acid & $43.9 \pm 0.95$ & Ferulic acid & $5.75 \pm 0.12$ \\
\hline & $p$-Coumaric acid & $7.39 \pm 0.17$ & $p$-Coumaric acid & $24.0 \pm 0.77$ \\
\hline & trans-Cinnamic acid & $1.99 \pm 0.04$ & Vitexin & $2.43 \pm 0.05$ \\
\hline & Vitexin & $11.4 \pm 0.53$ & & \\
\hline \multirow[t]{6}{*}{ Green mung bean } & Catechin & $7.31 \pm 0.58$ & Caffeic acid & $58.4 \pm 2.14$ \\
\hline & Gallic acid & $52.2 \pm 1.27$ & Ferulic acid & $9.39 \pm 0.23$ \\
\hline & $p$-Coumaric acid & $4.70 \pm 0.28$ & $p$-Coumaric acid & $47.1 \pm 1.75$ \\
\hline & trans-Cinnamic acid & $1.32 \pm 0.09$ & Vitexin & $1.43 \pm 0.04$ \\
\hline & Rutin & $88.5 \pm 8.70$ & & \\
\hline & Vitexin & $4.03 \pm 0.45$ & & \\
\hline \multirow[t]{3}{*}{ Green pea } & Gallic acid & $19.8 \pm 0.55$ & Ellagic acid & $9.68 \pm 0.91$ \\
\hline & trans-Cinnamic acid & $1.25 \pm 0.01$ & Ferulic acid & $2.02 \pm 0.02$ \\
\hline & & & $p$-Coumaric acid & $1.56 \pm 0.03$ \\
\hline \multirow{3}{*}{ Mottled pea } & Gallic acid & $16.4 \pm 0.60$ & Ellagic acid & $9.31 \pm 0.08$ \\
\hline & trans-Cinnamic acid & $0.75 \pm 0.01$ & Ferulic acid & $2.06 \pm 0.01$ \\
\hline & & & $p$-Coumaric acid & $1.32 \pm 0.02$ \\
\hline \multirow[t]{2}{*}{ White pea } & Gallic acid & $16.2 \pm 0.16$ & Ferulic acid & $2.24 \pm 0.02$ \\
\hline & trans-Cinnamic acid & $1.42 \pm 0.04$ & $p$-Coumaric acid & $1.37 \pm 0.02$ \\
\hline \multirow[t]{5}{*}{ Rice bean } & Catechin & $2.40 \pm 0.10$ & Ferulic acid & $2.49 \pm 0.04$ \\
\hline & Epicatechin & $8.52 \pm 0.38$ & $p$-Coumaric acid & $4.93 \pm 0.23$ \\
\hline & Gallic acid & $26.7 \pm 1.00$ & & \\
\hline & $p$-Coumaric acid & $3.20 \pm 0.11$ & & \\
\hline & trans-Cinnamic acid & $1.73 \pm 0.20$ & & \\
\hline
\end{tabular}




\begin{tabular}{cccccc}
\hline \multirow{2}{*}{ Sprouts } & \multicolumn{2}{c}{ Solvent-soluble fraction } & & \multicolumn{2}{c}{ Solvent-insoluble fraction } \\
\cline { 2 - 3 } \cline { 5 - 6 } & $\begin{array}{c}\text { Phenolic } \\
\text { compounds }\end{array}$ & $\begin{array}{c}\text { Content } \\
(\mathbf{m g} / \mathbf{1 0 0} \mathbf{~ g ~ D W})\end{array}$ & & $\begin{array}{c}\text { Phenolic } \\
\text { compounds }\end{array}$ & $\begin{array}{c}\text { Content } \\
(\mathbf{m g} / \mathbf{1 0 0} \mathbf{g} \text { DW })\end{array}$ \\
\hline Black soy bean & Ellagic acid & $45.6 \pm 3.15$ & & Ferulic acid & $2.92 \pm 0.05$ \\
& Gallic acid & $5.62 \pm 0.14$ & & $p$-Coumaric acid & $6.04 \pm 0.30$ \\
& $p$-Coumaric acid & $2.67 \pm 0.01$ & & Syringic acid & $2.10 \pm 0.11$ \\
& trans-Cinnamic acid & $1.77 \pm 0.10$ & & Vanillic acid & $3.53 \pm 0.18$ \\
Yellow soy bean & Ellagic acid & $48.9 \pm 3.57$ & & Ferulic acid & $3.77 \pm 0.12$ \\
& Gallic acid & $7.03 \pm 0.20$ & & p-Coumaric acid & $8.71 \pm 0.53$ \\
& $p$-Coumaric acid & $2.68 \pm 0.02$ & & Syringic acid & $6.65 \pm 0.35$ \\
& trans-Cinnamic acid & $1.63 \pm 0.13$ & & Vanillic acid & $4.26 \pm 0.32$ \\
\hline
\end{tabular}

\section{Correlation analysis among total antioxidant capacities and phenolic content in bean sprouts}

A positive correlation between antioxidant capacity and TPC has been demonstrated in fruits, vegetables, flowers, red rice, spices and medicinal plants [22, 26-30]. In this study, the correlations among the total iron-reducing capacity (FRAP value), free-radical scavenging capacity (ABTS value) and TPC in twelve edible bean sprouts were investigated (Figure 1). There was a positive correlation between FRAP and ABTS values $\left(\mathrm{R}^{2}=0.84, p<0.05\right)$, indicating that antioxidants in edible bean sprouts can not only reduce oxidants, but also scavenge free radicals. Additionally, the antioxidant capacity indicated by FRAP and ABTS values was also positively correlated with the TPC, with $\mathrm{R}^{2}=0.83$ and 0.78 ( $p<0.05$ ), respectively. This suggested that phenolic compounds, such as phenolic acids and flavonoids detected by HPLC, were the main contributors to the antioxidant capacity of bean sprouts.

Figure 1. Relationships between total antioxidant capacity and phenolic content in twelve edible bean sprouts.
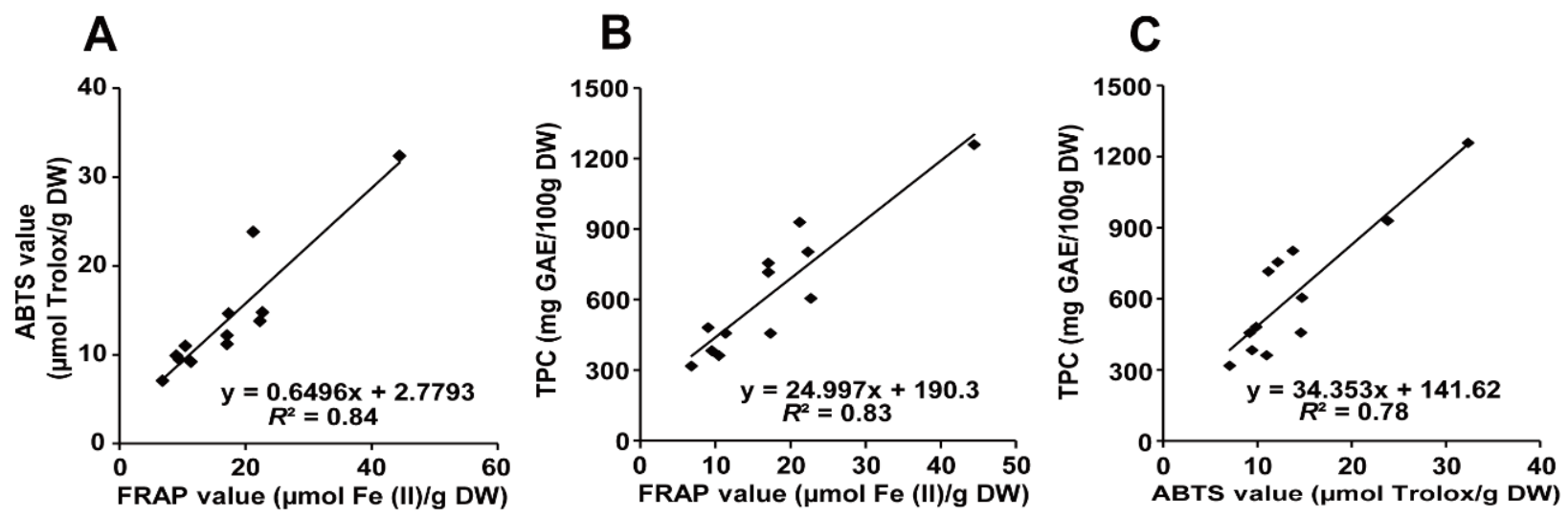

Linear regression was used to analyze the relationship among total antioxidant capacity and phenolic content. A. Correlation between total ferric-reducing antioxidant power (FRAP) and ABTS free radical scavenging (ABTS) values. B. Correlation between total FRAP value and total phenolic content (TPC). C. Correlation between total ABTS value and TPC. DW, dry weight. GAE, gallic acid equivalent.

\section{Principal component analysis}

In order to further select bean sprouts as potential dietary sources of antioxidant phenolics, principal component analysis (PCA) was performed to cluster six factors, including antioxidant 

capacity (FRAP and ABTS values) and TPC in both soluble and insoluble fractions of sprouts. Based on the results of Kaiser-Meyer-Olkin (KMO) and Bartlett's Test (KMO value $=0.655, p<$ 0.001 ), as well as communalities of each factor with extraction $>0.80$, data were generally satisfied with the requirements of PCA. The results revealed that one component (C1) including all six factors was extracted to explain $90.5 \%$ cumulative variance of six factors, suggesting that all six factors were closely correlated with each other, generally consistent with the results of correlation analysis. Additionally, the factor score (FS) in $\mathrm{C} 1$ represented a weighted antioxidant capacity and TPC of samples, and a higher FS indicated that the sample in general had higher antioxidant phenolics. As shown in Table 5, the green mung bean sprout had the highest FS, followed by the black mung bean sprout, mottled cowpea sprout, and speckled kidney bean sprout, while the white pea sprout had the lowest FS. Moreover, the commonly consumed soybean sprouts ranked in the middle among twelve sprouts. Therefore, the commonly consumed green mung bean sprout could be a good dietary source of antioxidant phenolics.

Table 5. Factor scores of 12 edible bean sprouts

\begin{tabular}{clll}
\hline Rank & \multicolumn{1}{c}{ Common name } & \multicolumn{1}{c}{ Scientific name } & FS of C1 \\
\hline $\mathbf{1}$ & Green mung bean & Vigna radiata & $\mathbf{2 . 7 5}$ \\
$\mathbf{2}$ & Black mung bean & Vigna radiata & $\mathbf{0 . 7 8}$ \\
$\mathbf{3}$ & Mottled cowpea & Vigna unguiculata & $\mathbf{0 . 1 3}$ \\
$\mathbf{4}$ & Speckled kidney bean & Phaseolus vulgaris & $\mathbf{0 . 1 2}$ \\
$\mathbf{5}$ & Adzuki bean & Vigna angularis & $\mathbf{0 . 0 1}$ \\
$\mathbf{6}$ & Climbing bean & Vigna angularis & $\mathbf{0 . 0 0}$ \\
$\mathbf{7}$ & Yellow soy bean & Glycine max & $\mathbf{- 0 . 1 1}$ \\
$\mathbf{8}$ & Black soy bean & Glycine max & $\mathbf{- 0 . 5 6}$ \\
$\mathbf{9}$ & Green pea & Pisum sativum & $\mathbf{- 0 . 6 5}$ \\
$\mathbf{1 0}$ & Rice bean & Vigna umbellata & $\mathbf{- 0 . 6 7}$ \\
$\mathbf{1 1}$ & Mottled pea & Pisum sativum & $\mathbf{- 0 . 8 0}$ \\
$\mathbf{1 2}$ & White pea & Pisum sativum & $\mathbf{- 1 . 0 0}$ \\
\hline
\end{tabular}

Factor scores (FS) of component 1 (C1) were listed from high to low. Principal component analysis (PCA) was used to cluster six factors of antioxidant capacity and TPC in both soluble and insoluble fractions of bean sprouts. One component (C1) was found to explain $90.5 \%$ cumulative variance of six factors, and the FS of $\mathrm{C} 1$ were calculated.

\section{Impact of germination on the antioxidant capacity and TPC of edible beans}

Germination has been reported to influence the antioxidant phenolics in germinated seeds, but results were inconsistent across different studies $[8,10,11]$, and this could be partly due to the different inherent characteristics of different seeds, in addition to the results expressed as fresh weight or dry weight. In this study, the antioxidant capacity and TPC in soaked beans without germination (Day 0) were also determined and compared with bean sprouts (Day 5). Generally, 
most bean sprouts had higher antioxidant capacity and TPC than respective soaked beans in both fractions (Table 1 and Table 2), indicating that germination could accumulate antioxidant phenolics in most edible bean sprouts, in agreement with Pajak et al. reported [8].

On the other hand, results differed on the specific impact of germination on the total antioxidant capacity and phenolic content in different beans, as indicated by Figure 2. It was interesting to find that, although the two soaked mung beans had very low total antioxidant capacity and phenolic content (Table 1 and Table 2), germination could significantly increase their total antioxidant capacity and phenolic content (Figure 2), especially for the green mung bean, and this might be partly due to the fast synthesis of phenolic compounds in mung bean sprouts, such as gallic acid, caffeic acid and $p$-coumaric acid and rutin [19]. Overall, germination could be a good way to

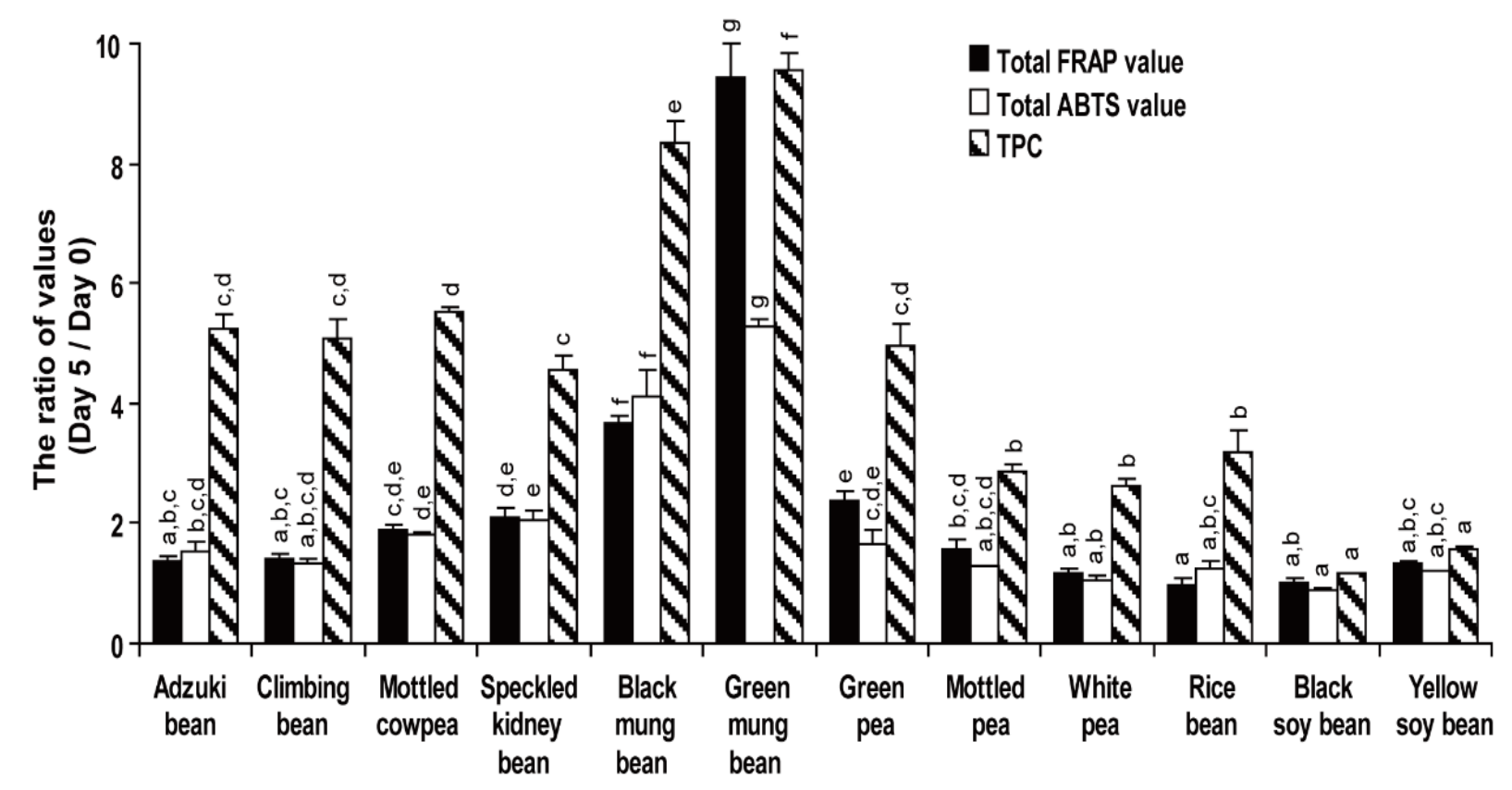

accumulate antioxidant phenolics in most selected edible bean sprouts.

Figure 2. The impact of germination on total antioxidant capacity and phenolic content in twelve edible beans

FRAP, total ferric-reducing antioxidant power; ABTS, ABTS free radical scavenging capacity, TPC, total phenolic content. One-way ANOVA plus post hoc Tukey test was performed for multiple comparisons within each value ratio, and results with different lowercase letters indicated statistical significance $(p<$ $0.05)$.

\section{CONCLUSIONS}

In summary, this work systematically evaluated the antioxidant capacity and TPC in soluble and insoluble fractions of twelve edible bean sprout genotypes. Generally, germination led to the accumulation of antioxidant phenolics in most selected bean sprouts, and the green mung bean sprout was discovered to have the highest total antioxidant capacity and phenolic content among these sprouts. Considering the health benefits of antioxidant phenolics, bean sprouts with high 
antioxidant phenolics can be consumed as functional vegetables for the prevention of oxidative stress-related chronic diseases.

Abbreviations: ABTS: 2,2'-azinobis(3-ethylbenothiazoline-6-sulfonic acid) diammonium salt; ANOVA:one-way analysis of variance; C1:component 1; DE:diethyl ether; DW: dry weight; EA: ethyl acetate; FRAP: ferric-reducing antioxidant power; FS:factor score; GAE: gallic acid equivalent; $\mathrm{HCl}$ :hydrochloric acid; HPLC, high-performance liquid chromatography; KMO:Kaiser-Meyer-Olkin; $\mathrm{NaOH}$ :sodium hydroxide; PCA: principal component analysis; SD: standard deviation; TPC: total phenolic content; TPTZ: 2,4,6-tri(2-pyridyl)-s-triazine; Trolox:6-hydroxy-2,5,7,8-tetramethylchromane-2-carboxylic acid.

Acknowledgments and Funding: This work was financially supported by grants from Special National Key Research and Development Plan (2016YFD0400206 to Z.Q.S.) of China, and Hong Kong Research Grants Council (RGC) (GRF17164716 to H.C.). We also thank Ms. Ming-Wei Fong (School of Biological Sciences, the University of Hong Kong) for her technical support in this study.

Author's Contributions: R.Y.G. and H.C. conceived and designed the experiments; R.Y.G. performed the experiments and analyzed the data; W.Y.L. and M.F.W. contributed to reagents and analysis tools; R.Y.G., Z.Q.S. and H.C. wrote and revised the manuscript.

Conflicts of Interest: The authors declare no conflict of interest.

\section{REFERENCES}

1. Hung HC, Joshipura KJ, Jiang R, Hu FB, Hunter D, Smith-Warner SA, Colditz GA, Rosner B, Spiegelman D, Willett WC: Fruit and vegetable intake and risk of major chronic disease. J Natl Cancer I 2004, 96:1577-1584.

2. Boeing H, Bechthold A, Bub A, Ellinger S, Haller D, Kroke A, Leschik-Bonnet E, Muller MJ, Oberritter H, Schulze M, Stehle P, Watzl B: Critical review: Vegetables and fruit in the prevention of chronic diseases. Eur J Nutr 2012, 51:637-663.

3. Shi HL, Nam PK, Ma YF: Comprehensive profiling of isoflavones, phytosterols, tocopherols, minerals, crude protein, lipid, and sugar during soybean (Glycine max) germination. J Agr Food Chem 2010, 58:4970-4976.

4. Li LM, Liu BG, Zheng XL: Bioactive ingredients in adzuki bean sprouts. J Med Plants Res 2011, 5:5894-5898.

5. Huang XY, Cai WX, Xu BJ: Kinetic changes of nutrients and antioxidant capacities of germinated soybean (Glycine max L.) and mung bean (Vigna radiata L.) with germination time. Food Chem 2014, 143:268-276.

6. Khattak AB, Zeb A, Bibi N, Khalil SA, Khattak MS: Influence of germination techniques on phytic acid and polyphenols content of chickpea (Cicer arietinum L.) sprouts. Food Chem 2007, 104:1074-1079.

7. Aguilera Y, Diaz MF, Jimenez T, Benitez V, Herrera T, Cuadrado C, Martin-Pedrosa M, Martin-Cabrejas MA: Changes in nonnutritional factors and antioxidant activity during 

germination of nonconventional legumes. J Agr Food Chem 2013, 61:8120-8125.

8. Pajak P, Socha R, Galkowska D, Roznowski J, Fortuna T: Phenolic profile and antioxidant activity in selected seeds and sprouts. Food Chem 2014, 143:300-306.

9. Lopez-Amoros ML, Hernandez T, Estrella I: Effect of germination on legume phenolic compounds and their antioxidant activity. J Food Compos Anal 2006, 19: 277-283.

10.Cevallos-Casals BA, Cisneros-Zevallos L: Impact of germination on phenolic content and antioxidant activity of 13 edible seed species. Food Chem 2010, 119:1485-1490.

11.Guajardo-Flores D, Serna-Saldivar SO, Gutierrez-Uribe JA: Evaluation of the antioxidant and antiproliferative activities of extracted saponins and flavonols from germinated black beans (Phaseolus vulgaris L.). Food Chem 2013, 141:1497-1503.

12.Guo, XB, Li T, Tang KX, Liu RH: Effect of germination on phytochemical profiles and antioxidant activity of mung bean sprouts (Vigna radiata). J Agr Food Chem 2012, 60:11050-11055.

13.Wu ZY, Song LX, Feng SB, Liu YC, He GY, Yioe Y, Liu SQ, Huang DJ: Germination dramatically increases isoflavonoid content and diversity in chickpea (Cicer arietinum L.) seeds. J Agr Food Chem 2012, 60:8606-8615.

14.Gharachorloo M, Tarzi BG, Baharinia M: The effect of germination on phenolic compounds and antioxidant activity of pulses. J Am Oil Chem Soc 2013, 90:407-411.

15.Swieca M, Baraniak B: Nutritional and antioxidant potential of lentil sprouts affected by elicitation with temperature stress. J Agr Food Chem 2014, 62:3306-3313.

16. Madhujith T, Shahidi F: Antioxidant potential of barley as affected by alkaline hydrolysis and release of insoluble-bound phenolics. Food Chem 2009, 117:615-620.

17. Chandrasekara A, Shahidi F: Content of insoluble bound phenolics in millets and their contribution to antioxidant capacity. J Agr Food Chem 2010, 58:6706-6714.

18.Ti HH, Zhang RF, Zhang MW, Li Q, Wei ZC, Zhang Y, Tang XJ, Deng YY, Liu L, Ma YX: Dynamic changes in the free and bound phenolic compounds and antioxidant activity of brown rice at different germination stages. Food Chem 2014, 161:337-344.

19.Gan RY, Wang MF, Lui WY, Wu K, Corke H: Dynamic changes in phytochemical composition and antioxidant capacity in green and black mung bean (Vigna radiata) sprouts. Int J Food Sci Tech 2016, doi:10.1111/ijfs.13185, in press.

20.Gan RY, Lui WY, Corke H: Sword bean (Canavalia gladiata) as a source of antioxidant phenolics. Int J Food Sci Tech 2016, 51:156-162.

21.Benzie IFF, Strain JJ: The ferric reducing ability of plasma (FRAP) as a measure of "antioxidant power": The FRAP assay. Anal Biochem 1996, 239:70-76.

22.Gan RY, Kuang L, Xu XR, Zhang YA, Xia EQ, Song FL, Li HB: Screening of natural antioxidants from traditional Chinese medicinal plants associated with treatment of rheumatic disease. Molecules 2010, 15:5988-5997.

23.Re R, Pellegrini N, Proteggente A, Pannala A, Yang M, Rice-Evans C: Antioxidant activity applying an improved ABTS radical cation decolorization assay. Free Radical Bio Med 1999, 26:1231-1237.

24.Singleton VL, Rossi JA: Colorimetry of total phenolics with phosphomolybdic -phosphotungstic acid reagents. Am J Enol Vitic 1965, 16:144-158. 
25.Deng GF, Xu XR, Guo YJ, Xia EQ, Li S, Wu S, Chen F, Ling WH, Li HB: Determination of antioxidant property and their lipophilic and hydrophilic phenolic contents in cereal grains. J Funct Foods 2012, 4:906-914.

26.Li AN, Li S, Li HB, Xu DP, Xu XR, Chen F: Total phenolic contents and antioxidant capacities of 51 edible and wild flowers. J Funct Foods 2014, 6:319-330.

27. Shan B, Cai YZ, Sun M, Corke H: Antioxidant capacity of 26 spice extracts and characterization of their phenolic constituents. J Agr Food Chem 2005, 53:7749-7759.

28.Fu L, Xu BT, Xu XR, Gan RY, Zhang Y, Xia EQ, Li HB: Antioxidant capacities and total phenolic contents of 62 fruits. Food Chem 2011, 129:345-350.

29.Deng GF, Lin X, Xu XR, Gao LL, Xie JF, Li HB: Antioxidant capacities and total phenolic contents of 56 vegetables. J Funct Foods 2013, 5:260-266.

30.Gunaratne A, Wu K, Li DQ, Bentota A, Corke H, Cai YZ: Antioxidant activity and nutritional quality of traditional red-grained rice varieties containing proanthocyanidins. Food Chem 2013, 138:1153-1161. 